\title{
House and Household Economies in 3rd millennium B.C.E. Syro-Mesopotamia
}

\author{
edited by Federico Buccellati, Tobias Helms and Alexander Tamm
}

iv+132 pages; illustrated throughout in black \& white

BAR S2682 2014. ISBN 9781407313283. $£ 27.00$

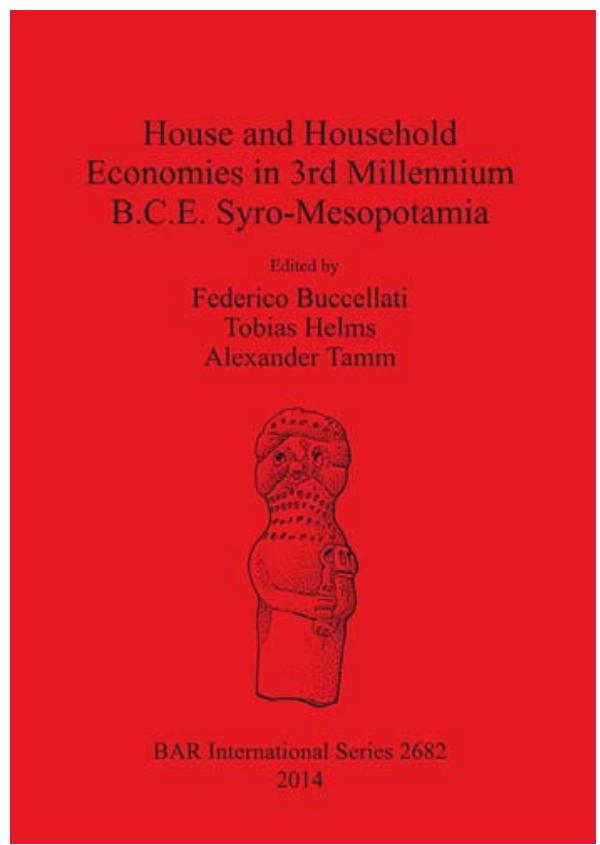

Provision for Contributors, $40 \%$ Discount post free until 31/01/15 (35\% plus post thereafter)

Please post to: Archaeopress, 276 Banbury Road, Oxford, UK, OX2 7ED, fax: +44 (0) 1865512331 or email: archaeo@archaeopress.com. Payments by Mastercard, Visa, or by $f$ (sterling) cheque (payable to Archaeopress)

Before 31/01/15: Please send me copy/ies of BAR $\mathbf{2 6 8 2}$ at $£ 16.20$ each (RRP $£ 27.00)$ post free

After 31/01/15: Please send me copy/ies of BAR 2682 at $£ 17.55$ each (RRP $£ 27.00)+$ standard rate $P \& P$ 